\title{
Soluble Epoxide Hydrolase 2 Expression Is Elevated in Obese Humans and Decreased by Physical Activity
}

\author{
Abdelkrim Khadir ${ }^{1,+}{ }^{\dagger}$, Sina Kavalakatt ${ }^{1,+}{ }^{,}$Dhanya Madhu ${ }^{1}$, Preethi Cherian ${ }^{1}$, \\ Fahd Al-Mulla ${ }^{2} \mathbb{D}$, Jehad Abubaker ${ }^{1}$ and Ali Tiss ${ }^{1, *}$ \\ 1 Biochemistry and Molecular Biology Department, Research Division, Dasman Diabetes Institute, \\ Kuwait City 15462, Kuwait; abdelkrim.khadir@dasmaninstitute.org (A.K.); \\ sina.kavalakatt@dasmaninstitute.org (S.K.); dhanya.madhu@dasmaninstitute.org (D.M.); \\ preethi.cherian@dasmaninstitute.org (P.C.); jehad.abubakr@dasmaninstitute.org (J.A.) \\ 2 Research Division, Dasman Diabetes Institute, Kuwait City 15462, Kuwait; \\ fahd.almulla@dasmaninstitute.org \\ * Correspondence: ali.tiss@dasmaninstitute.org; Tel.: +965-222-429-99 (ext. 3553) \\ + These authors contributed equally to this work.
}

Received: 28 January 2020; Accepted: 28 February 2020; Published: 17 March 2020

\begin{abstract}
Epoxide hydrolase 2 (EPHX2) is an emerging therapeutic target in several immunometabolic disorders. EPHX2 metabolizes anti-inflammatory epoxyeicosatrienoic acids into pro-inflammatory diols. The contribution of EPHX2 activity to human obesity remains unexplored. We compared the expression of EPHX2 between lean and obese humans ( $n=20$ each) in subcutaneous adipose tissue (SAT) and peripheral blood mononuclear cells (PBMCs) using RT-PCR, Western Blot analysis, immunohistochemistry, and confocal microscopy before and after a 3-month physical activity regimen. We also assessed EPHX2 levels during preadipocyte differentiation in humans and mice. EPHX2 mRNA and protein expression were significantly elevated in obese subjects, with concomitant elevated endoplasmic reticulum (ER) stress components (the 78-kDa glucose-regulated protein; GRP78, and the Activating transcription factor 6; ATF6) and inflammatory markers (Tumor necrosis factor- $\alpha$; TNF $\alpha$, and Interleukin 6; IL6) as compared to controls $(p<0.05)$. EPHX2 mRNA levels strongly correlated with adiposity markers. In obese individuals, physical activity attenuated EPHX2 expression levels in both the SAT and PBMCs, with a parallel decrease in ER stress and inflammation markers. EPHX2 expression was also elevated during differentiation of both human primary and 3T3-L1 mouse preadipocytes. Mediators of cellular stress (palmitate, homocysteine, and macrophage culture medium) also increased EPHX2 expression in 3T3-L1 preadipocytes. Our findings suggest that EPHX2 upregulation is linked to ER stress in adiposity and that physical activity may attenuate metabolic stress by reducing EPHX2 expression.
\end{abstract}

Keywords: EPHX2; sEH; obesity; diabetes; exercise

\section{Introduction}

Soluble epoxide hydrolase 2 (EPHX2), with dual epoxide hydrolase and lipid phosphatase activities, is an emerging therapeutic target in several diseases that share chronic metaflammation as the underlying cause [1]. EPHX2 exerts pro-inflammatory activity by metabolizing anti-inflammatory epoxyeicosatrienoic acids (EETs) into the less active dihydroxyeicosatrienoic acids (DHETs). Together with cyclooxygenase and lipoxygenase, EPHX2 is involved in the arachidonic acid metabolic cascade [2]. One strategy for increasing the action of EETs involves decreasing the activity of EPHX2 [3]. 
EPHX2 plays further roles in glucose homeostasis, obesity, and diabetes, as shown in rodent and cell-line models [4]. Both the gene deletion and pharmacological inhibition of EPHX2 result in the preservation of islet cells in rodent models of type 1 diabetes and an increase in insulin sensitivity in type 2 diabetes (T2D) models, as does the direct administration of EETs [4]. A study in humans reported that the EPHX2(K55R) variant, which results in elevated EPHX2 activity, increases the risk of congenital heart disease in Caucasians [5]. The variant EPHX2(R287Q) is associated with an increased risk of obesity and coronary artery calcification in humans [6]. Furthermore, the increased expression and activity of EPHX2 results in decreased EET levels and thus the EPHX2/EET pathway contributes to obesity and diabetes-induced endothelial dysfunction and cardiovascular disease [7].

Plasma EET levels were found to correlate with insulin sensitivity, and carriers of a loss-of-function polymorphism in EPHX2 $(R 287 Q)$ demonstrated increased insulin sensitivity, suggesting that EPHX2 inhibition might benefit humans at risk of T2D [8]. In contrast, the same variant was reported to be associated with insulin resistance in Japanese patients with T2D [9]. This discrepancy indicates that factors such as ethnicity, diabetes, obesity, and environment affect the activity of EPHX2 in humans. Nevertheless, the functional contribution of EPHX2 and its anti-inflammatory substrates to human obesity remains poorly understood. Interestingly, gut bacteria were recently reported to be implicated in the regulation of EPHX2 activity [10]. Accordingly, the strong reduction of EPHX2 activity in postprandial states in rats was completely abolished in rats treated with antibiotics to deplete gut bacteria. This effect seems to be insulin-independent and the gut bacteria-derived factors are yet to be elucidated [10].

Physical activity is an important non-pharmacological intervention for managing chronic lifestyle-related diseases, such as obesity and diabetes. While the beneficial effects of exercise are well documented and evidence indicates that regular exercise is a viable, cost effective but underused treatment [11], the related molecular mechanisms are not yet fully understood [12,13]. Reports addressing circulating concentrations of EPHX2 and its metabolites in response to exercise in humans are scarce. Moreover, whether regular exercise affects EPHX2 expression or circulating EET levels in obesity and diabetes is still elusive. A previous report showed that submaximal exercise on a bicycle induced the release of stable DHET metabolites in healthy human volunteers [14]. A more recent study in healthy humans reported that short-term maximal exercise increased the release and accumulation of plasma DHETs but did not alter EPHX2 activity [15]. In addition, exercise-induced vasodilatation in skeletal muscles is reported to release EETs under endothelial nitric oxide synthase inhibition [16].

Given the potential involvement of EPHX2 in obesity and diabetes, we hypothesize that EPHX2 levels in obese humans are elevated over those of normal-weight individuals. This study aims to evaluate the expression levels of EPHX2 in peripheral blood mononuclear cells (PBMCs) and the subcutaneous adipose tissue (SAT) of normal-weight and obese subjects and to investigate the effect of exercise on its expression. We also investigate EPHX2 expression levels during preadipocyte differentiation and the effects of cellular stressors (palmitate and homocysteine) on EPHX2 expression in adipocytes cell lines.

\section{Results}

\subsection{Characteristics of the Study Population and the Effects of Exercise}

The study cohort included 40 subjects without diabetes, of which 20 were of normal weight and 20 were obese. Plasma, PBMCs, and SAT biopsies were collected from subjects. In addition, all members of the obese group were enrolled in a 3-month regular physical activity regimen. Characteristics of the study population at baseline are summarized in Table 1 . The obese group displayed significantly higher systolic blood pressure and lower $\mathrm{VO}_{2 \max }$ compared with the normal-weight (Lean) group $(p<0.05)$. In addition, the former group showed a dysregulated lipid profile, as reflected by higher TG $(p=0.008)$ and lower high-density lipoprotein (HDL) concentrations $(p=0.015)$ as compared to that 
of the normal-weight group. Obese subjects also showed higher concentrations of glycemic markers (fasting blood glucose, $\mathrm{HbA1c}$, insulin, and HOMA-IR) compared with the normal-weight subjects $(p<0.05$, Table 1$)$. While the circulating concentrations of inflammatory and stress markers were also elevated in the obese group, only hsCRP and GRP78 concentrations differed significantly $(p<0.001$ and $p=0.012$, respectively).

Table 1. Physical, clinical, and biochemical characteristics of the cohort study at baseline.

\begin{tabular}{|c|c|c|c|}
\hline Marker & $\begin{array}{c}\text { Lean }(n=20) \\
(\text { Mean } \pm \mathrm{SD}, n=20)\end{array}$ & $\begin{array}{c}\text { Obese }(n=20) \\
(\text { Mean } \pm \text { SD, } n=20)\end{array}$ & $(p$-Value) \\
\hline \multicolumn{4}{|c|}{ Anthropometric and physical characteristics } \\
\hline AGE (year) & $38.75 \pm 9.60$ & $40.13 \pm 8.68$ & 0.55 \\
\hline Gender $(\mathrm{M} / \mathrm{F})$ & $8 / 12$ & $10 / 10$ & 0.37 \\
\hline $\operatorname{BMI}\left(\mathrm{kg} / \mathrm{m}^{2}\right)$ & $22.72 \pm 2.09$ & $34.83 \pm 2.99$ & $<0.001$ \\
\hline Waist (cm) & $79.45 \pm 15.96$ & $108.52 \pm 13.71$ & $<0.001$ \\
\hline Hip $(\mathrm{cm})$ & $92.07 \pm 14.98$ & $118.15 \pm 8.29$ & $<0.001$ \\
\hline PBF $(\%)$ & $27.50 \pm 5.35$ & $39.36 \pm 5.12$ & $<0.001$ \\
\hline $\mathrm{SBP}(\mathrm{mmHg})$ & $113.00 \pm 10.81$ & $127.50 \pm 11.89$ & 0.01 \\
\hline $\mathrm{DBP}(\mathrm{mmHg})$ & $76.43 \pm 6.33$ & $82.00 \pm 10.14$ & 0.13 \\
\hline $\mathrm{V}_{\mathrm{O} 2, \operatorname{Max}}(\mathrm{mL} / \mathrm{kg} / \mathrm{min})$ & $21.63 \pm 3.76$ & $16.54 \pm 4.83$ & 0.03 \\
\hline \multicolumn{4}{|c|}{ Metabolic markers } \\
\hline Cholesterol (mmol/L) & $5.22 \pm 0.91$ & $5.38 \pm 1.10$ & 0.74 \\
\hline $\mathrm{HDL}(\mathrm{mmol} / \mathrm{L})$ & $1.48 \pm 0.53$ & $1.19 \pm 0.26$ & 0.015 \\
\hline LDL (mmol/L) & $3.23 \pm 0.91$ & $3.39 \pm 0.98$ & 0.28 \\
\hline $\mathrm{TG}(\mathrm{mmol} / \mathrm{L})$ & $0.91 \pm 0.42$ & $1.47 \pm 0.83$ & 0.008 \\
\hline Glucose (mmol/L) & $5.0 \pm 0.5$ & $5.7 \pm 0.7$ & 0.013 \\
\hline HbA1c (\%) & $5.50 \pm 0.44$ & $5.93 \pm 0.48$ & 0.014 \\
\hline Insulin (ng/mL) & $2.6 \pm 1.3$ & $4.2 \pm 2.5$ & 0.029 \\
\hline HOMA-IR & $0.7 \pm 0.5$ & $1.1 \pm 0.7$ & 0.025 \\
\hline \multicolumn{4}{|c|}{ Inflammatory markers } \\
\hline IL-6 (pg/mL) & $17.06 \pm 2.9$ & $17.40 \pm 4.4$ & 0.39 \\
\hline TNF-a (pg/mL) & $123.52 \pm 35$ & $126.47 \pm 43$ & 0.94 \\
\hline hsCRP $(\mu \mathrm{g} / \mathrm{mL})$ & $1.7 \pm 1.2$ & $5.3 \pm 3.6$ & $<0.001$ \\
\hline \multicolumn{4}{|c|}{ Stress markers } \\
\hline GRP78 $(\mu \mathrm{g} / \mathrm{mL})$ & $0.925 \pm 0.95$ & $1.2 \pm 0.75$ & 0.012 \\
\hline HSP72 (ng/mL) & $1.85 \pm 0.53$ & $1.62 \pm 0.45$ & 0.055 \\
\hline
\end{tabular}

Abbreviations: ATF6, activating transcription factor 6; BMI, body mass index; DBP, diastolic blood pressure; EPHX2, epoxide hydrolase 2; GRP78, 78-kDa glucose-regulated protein; HbA1c, hemoglobin A1c; HDL, high-density lipoprotein; HOMA-IR, homeostatic model assessment of insulin resistance; hsCRP, high-sensitivity CRP; HSP72, heat shock protein 72; IL-6, interleukin 6; LDL, low-density lipoprotein; PBF, percent body fat; SBP, systolic blood pressure; TGL, triglyceride; TNF- $\alpha$, Tumor necrosis factor- $\alpha ; \mathrm{VO}_{2, \max }$, maximum oxygen consumption.

Table 2 summarizes the effect of exercise on the biochemical parameters of subjects in the obese group. After exercise, we observed a significant decrease in adiposity markers (waist circumference and PBF), glycemic index markers (insulin, HOMA-IR, and C-peptide) and systolic blood pressure, along with an increase in $\mathrm{VO}_{2}$ max, despite the absence of a prescribed diet. No significant changes were observed after exercise in the metabolic and inflammatory blood markers, except for a significant decrease in insulin and HOMA-IR concentrations $(p<0.05)$. 
Table 2. Physical, clinical, and biochemical characteristics of obese subjects without diabetes before and after exercise.

\begin{tabular}{|c|c|c|c|}
\hline Marker & $\begin{array}{c}\text { Obese before } \\
(\text { Mean } \pm \text { SD, } n=20)\end{array}$ & $\begin{array}{c}\text { Obese after } \\
(\text { Mean } \pm \text { SD, } n=20)\end{array}$ & $p$-Value \\
\hline \multicolumn{4}{|c|}{ Anthropometric and physical characteristics } \\
\hline BMI $\left(\mathrm{kg} / \mathrm{m}^{2}\right)$ & $34.83 \pm 2.99$ & $34.08 \pm 3.31$ & 0.09 \\
\hline Waist (cm) & $108.52 \pm 13.71$ & $105.17 \pm 10.97$ & 0.03 \\
\hline Hip $(\mathrm{cm})$ & $118.15 \pm 8.29$ & $116.57 \pm 9.05$ & 0.23 \\
\hline PBF (\%) & $39.36 \pm 5.12$ & $38.44 \pm 5.09$ & 0.02 \\
\hline $\mathrm{SBP}(\mathrm{mmHg})$ & $127.50 \pm 11.89$ & $117.22 \pm 8.20$ & 0.01 \\
\hline $\mathrm{DBP}(\mathrm{mmHg})$ & $82.00 \pm 10.14$ & $79.39 \pm 4.95$ & 0.08 \\
\hline \multicolumn{4}{|c|}{ Metabolic markers } \\
\hline Cholesterol (mmol/L) & $5.38 \pm 1.10$ & $5.37 \pm 1.22$ & 0.83 \\
\hline HDL (mmol/L) & $1.19 \pm 0.26$ & $1.29 \pm 0.49$ & 0.11 \\
\hline $\mathrm{LDL}(\mathrm{mmol} / \mathrm{L})$ & $3.39 \pm 0.98$ & $3.47 \pm 1.13$ & 0.69 \\
\hline $\mathrm{TG}(\mathrm{mmol} / \mathrm{L})$ & $1.47 \pm 0.83$ & $1.28 \pm 0.77$ & 0.17 \\
\hline Glucose $(\mathrm{mmol} / \mathrm{L})$ & $5.7 \pm 0.7$ & $5.5 \pm 0.6$ & 0.49 \\
\hline $\operatorname{HbA1c}(\%)$ & $5.93 \pm 0.48$ & $5.78 \pm 0.42$ & 0.28 \\
\hline Insulin (ng/mL) & $4.2 \pm 2.5$ & $3.30 \pm 1.11$ & 0.01 \\
\hline HOMA-IR & $1.1 \pm 0.7$ & $0.8 \pm 0.2$ & 0.04 \\
\hline \multicolumn{4}{|c|}{ Inflammatory markers } \\
\hline IL-6 (pg/mL) & $17.4 \pm 4.4$ & $16.6 \pm 6.5$ & 0.87 \\
\hline TNF-a (pg/mL) & $126.4 \pm 43$ & $123.8 \pm 33.1$ & 0.59 \\
\hline hsCRP $(\mu \mathrm{g} / \mathrm{mL})$ & $5.3 \pm 3.6$ & $6.2 \pm 4.1$ & 0.43 \\
\hline \multicolumn{4}{|c|}{ Stress markers } \\
\hline GRP78 $(\mu \mathrm{g} / \mathrm{mL})$ & $1.2 \pm 0.75$ & $0.85 \pm 0.26$ & 0.02 \\
\hline HSP72 (ng/mL) & $1.62 \pm 0.45$ & $2.08 \pm 0.59$ & 0.35 \\
\hline
\end{tabular}

Abbreviations: ATF6, activating transcription factor 6; BMI, body mass index; DBP, diastolic blood pressure; EPHX2, epoxide hydrolase 2; GRP78, 78-kDa glucose-regulated protein; HbA1c, hemoglobin A1c; HDL, high-density lipoprotein; HOMA-IR, homeostatic model assessment of insulin resistance; hsCRP, high-sensitivity CRP; HSP72, heat shock protein 72; IL-6, interleukin 6; LDL, low-density lipoprotein; PBF, percent body fat; SBP, systolic blood pressure; TGL, triglyceride; TNF- $\alpha$, Tumor necrosis factor- $\alpha$; $\mathrm{VO}_{2, \max }$, maximum oxygen consumption.

\subsection{EPHX2 Expression Levels Are Elevated in the PBMCs and SAT of Obese Subjects and Decrease with Physical Activity}

To elucidate the role of EPHX2 in obesity, we assessed its expression levels in PBMCs and SAT in normal-weight and obese individuals before and after exercise. EPHX2 mRNA expression levels were significantly higher in obese than in the normal-weight individuals $(p<0.05$, Figure 1A). However, EPHX2 expression decreased significantly in the obese group after exercise $(p<0.05)$. Comparable trends were also observed for the ER stress markers GRP78 and ATF6, as their concentrations were elevated in obese subjects and decreased by physical activity (Figure 1B,C). We also observed a trend of higher EPHX2 expression levels in the SAT of obese males than in females; however, these differences did not reach statistical significance (Figure S1).

We further investigated EPHX2 protein levels in SAT and the effect of exercise on these levels. Both immunohistochemical staining and confocal immunofluorescence revealed more intense EPHX2 staining in obese than in normal-weight SAT (Figure 2A,B). EPHX2 staining was mainly observed in the thin rim of adipocyte cytoplasm. Staining quantification also showed that exercise significantly decreased EPHX2 levels in obese subjects $(p<0.05)$. Comparable trends were also observed for the ER stress markers GRP78 and ATF6, as their expression levels in the SAT were significantly elevated in obesity and decreased after physical activity $(p<0.05)$ (Figure 2A,B). As a control, adiponectin mRNA and protein levels were also assessed in SAT samples from the same subjects; as expected, the converse profile was observed (data not shown). 
A

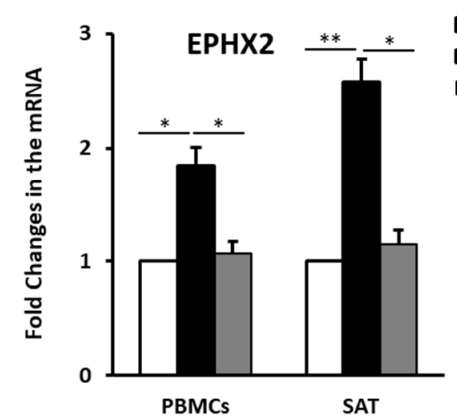

B

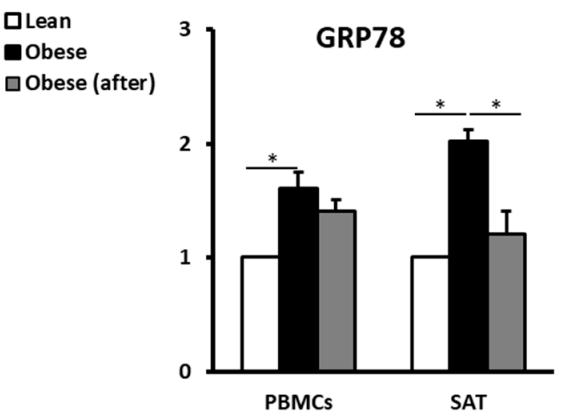

$C$

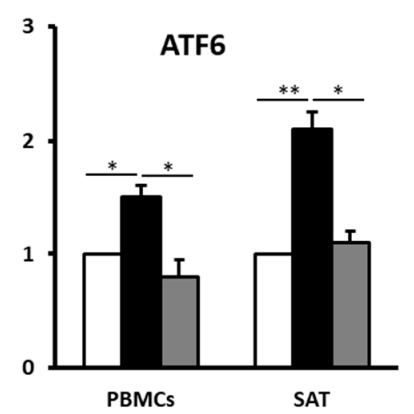

Figure 1. Epoxide hydrolase 2 (EPHX2) mRNA expression in subcutaneous adipose tissue (SAT) and peripheral blood mononuclear cells (PBMCs) from human subjects. mRNA expression of EPHX2 (A), the 78-kDa glucose-regulated protein (GRP78) (B), and the Activating transcription factor 6(ATF6) (C) in PBMCs and SAT of participant groups (lean, obese before exercise, and obese after exercise, $n=10$ each). mRNA levels were measured by quantitative real-time PCR. Glyceraldehyde 3-phosphate dehydrogenase (GAPDH) was used as an internal control for normalization. Data are presented as fold changes compared with normal-weight participants. ${ }^{*} p<0.05 ;{ }^{* *} p<0.01$.

EPHX2 and GRP78 expression in PBMCs was similar to that of SAT, with elevated levels in obese subjects that decreased after exercise $(p<0.05)$ (Figure 2C); despite some variation between the subjects was observed (Figure S2). ATF6 levels were not quantified due to the unsatisfactory quality of the Western Blot obtained (data not shown).

Spearman correlation analysis of EPHX2 mRNA levels in SAT with demographic and clinical parameters (Table 3) showed that EPHX2 levels correlated positively with adiposity markers (BMI, waist and hip circumferences, and PBF), SBP $(p<0.01)$, and circulating stress markers levels (GRP78 and HSP72) $(p<0.05)$ and negatively with $\mathrm{VO}_{2 \max }(p=0.016)$.

Table 3. Spearman correlation with EPHX2 mRNA.

\begin{tabular}{ccc}
\hline Markers & R-Value & $p$-Value \\
\hline BMI $\left(\mathrm{kg} / \mathrm{m}^{2}\right)$ & 0.73 & 0.001 \\
Waist $(\mathrm{cm})$ & 0.66 & 0.008 \\
Hip $(\mathrm{cm})$ & 0.51 & 0.004 \\
PBF (\%) & 0.54 & 0.002 \\
SBP $(\mathrm{mmHg})$ & 0.49 & 0.006 \\
DBP (mmHg) & 0.30 & 0.110 \\
$\mathrm{VO}_{2, \text { Max }(\mathrm{mL} / \mathrm{kg} / \mathrm{min})}$ & -0.44 & 0.016 \\
HSP72 & 0.43 & 0.020 \\
GRP78 & 0.52 & 0.002 \\
\hline
\end{tabular}

Abbreviations: BMI, body mass index; DBP, diastolic blood pressure; EPHX2, epoxide hydrolase 2; GRP78, 78-kDa glucose-regulated protein; HSP72, heat shock protein 72; PBF, percent body fat; $\mathrm{SBP}$, systolic blood pressure; $\mathrm{VO}_{2, \max }$ maximum oxygen consumption. 
A
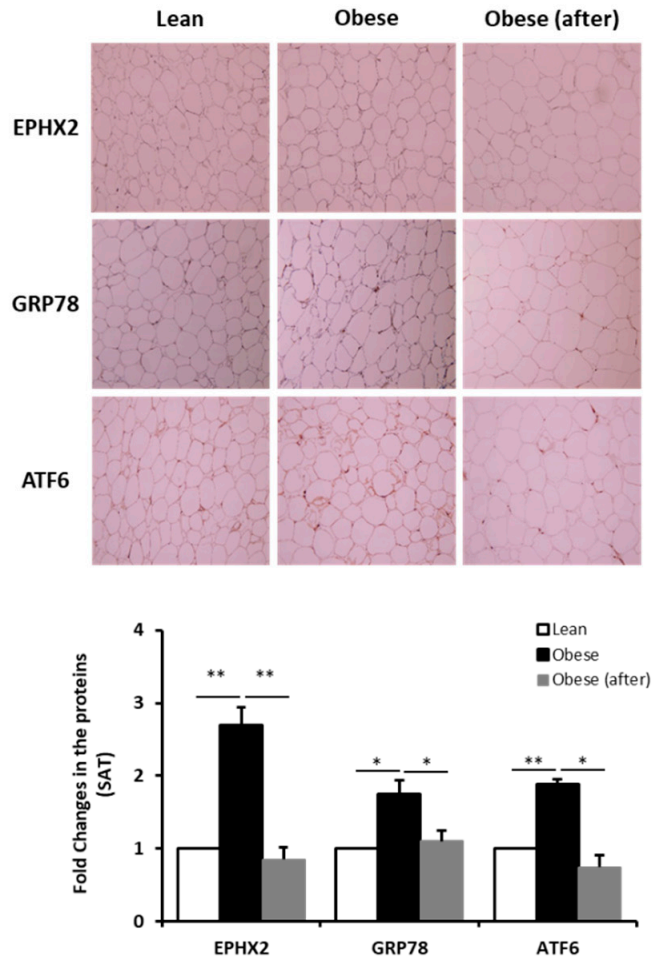

B
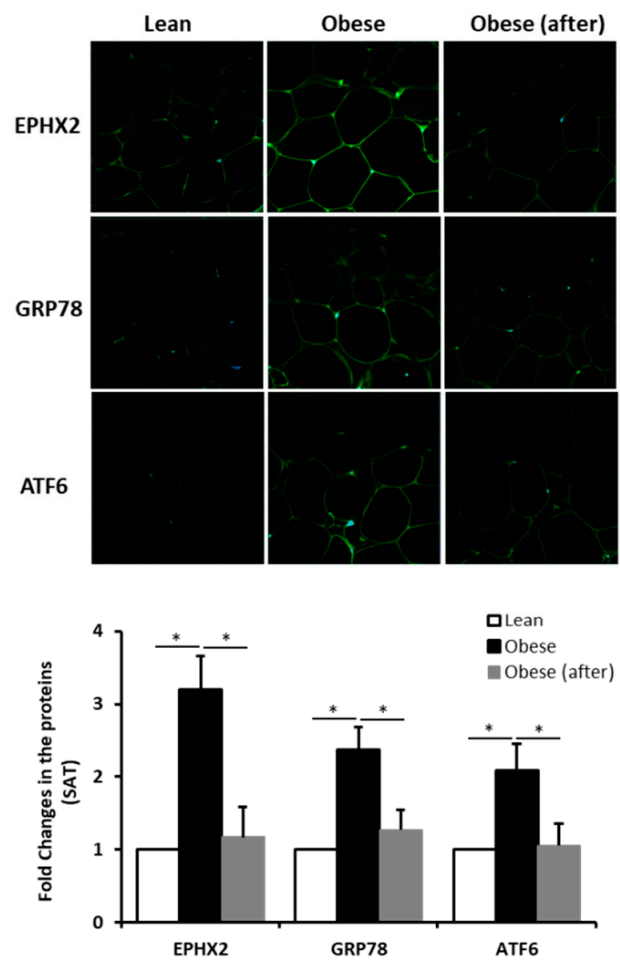

C
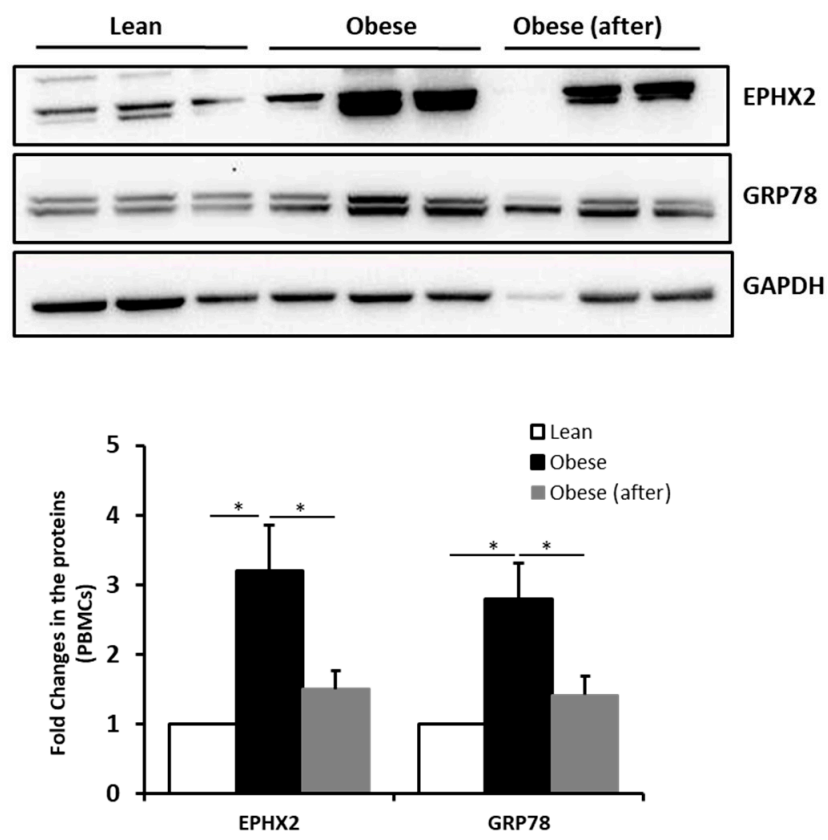

Figure 2. EPHX2 protein levels in SAT and PBMCs from human subjects. Representative immunohistochemical (A) and confocal immunofluorescence (B) images illustrating EPHX2, GRP78, and ATF6 expression and localization in SAT from lean, obese before exercise, and obese after exercise group ( $n=5$ each). Staining quantification of SAT was performed as detailed in Materials and Methods; data are presented as fold changes compared to the normal-weight group. (C) Protein expression of EPHX2, GRP78, and ATF6 in PBMCs according to groups (at least $n=9$ each). Protein levels were measured by Western Blotting. GAPDH was used as an internal control for normalization. Data are presented as fold changes compared to the lean participants. ${ }^{*} p<0.05 ;{ }^{* *} p<0.01$. 


\subsection{EPHX2 Expression Levels Increase during Preadipocyte Differentiation}

We assessed the expression levels of EPHX2 during differentiation in murine 3T3-L1 cells and human primary preadipocytes. In 3T3-L1 cells, both EPHX2 mRNA and protein were present in preadipocytes (day 0, D0) and adipocytes (day 14, D14), with expression levels that increased through the differentiation process (Figure 3A,B). Similarly, the levels of EPHX2 mRNA expression in human visceral (hVAT) and subcutaneous (hSAT) adipocytes increased during induced differentiation (day 0-10) (Figure 3C). Preadipocyte differentiation was monitored using O-Red-oil and AdipoRed staining in 3T3-L1 and human primary adipocytes, respectively (Figure S3).

A
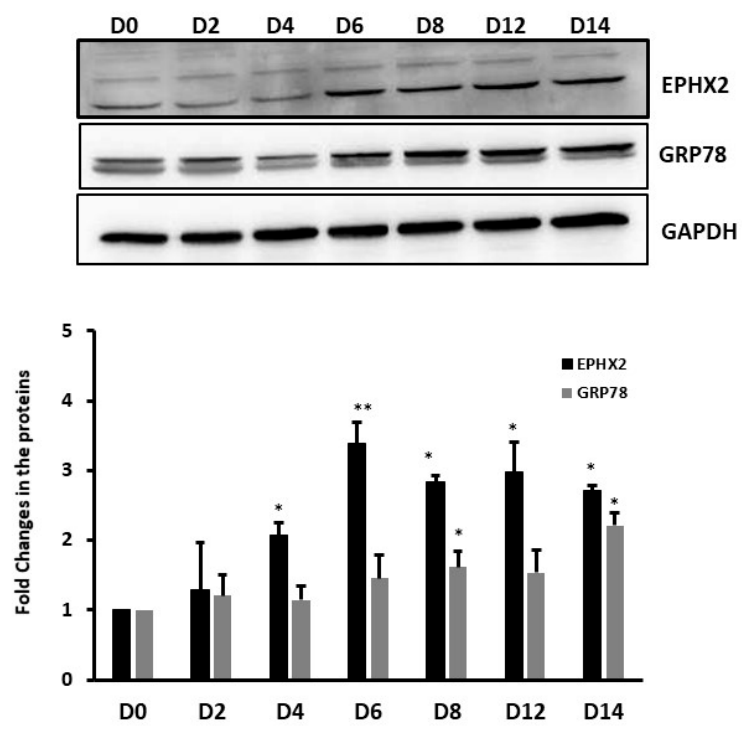

B

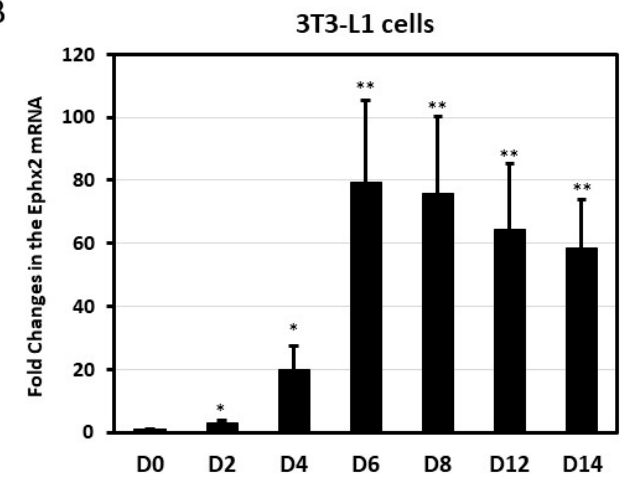

C

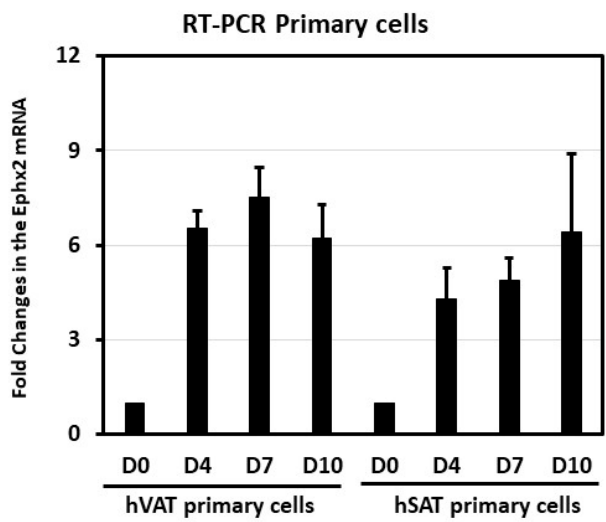

Figure 3. Expression levels of EPHX2 during differentiation of preadipocytes. Protein (A) and mRNA (B) levels were measured by Western Blot and quantitative real-time PCR, respectively, in 3T3-L1 preadipocytes (D0) and adipocytes differentiated for 14 days (D2-D14) from three independent experiments. (C) mRNA levels were measured by quantitative real-time PCR in human visceral (hVAT), subcutaneous (hSAT) preadipocytes (D0), and adipocytes differentiated for 10 days (D4-D10) from two independent experiments. Data are presented as the fold change in differentiated adipocytes compared with preadipocytes (D0). ${ }^{*} p<0.05{ }^{* *} p<0.01$.

We previously reported a different pattern for cellular stress and inflammatory markers in the SAT of normal-weight and obese individuals [17]. This observation, together with the correlation between EPHX2 expression and the cellular stress markers GRP78 and HSP72 observed in the present study, prompted us to investigate the effect of stress and inflammation inducers on EPHX2 expression during preadipocyte differentiation. We observed that the 3T3-L1 cells treated with homocysteine or palmitate displayed concentration-dependent increases in EPHX2 and GRP78 protein expression over those of untreated cells (Figure 4). Finally, 3T3-L1 preadipocytes cultured in macrophage-conditioned media (MaCM) further increased EPHX2 mRNA levels in differentiated adipocytes $(p<0.05)$, GRP78, and ATF6 (Figure 5). Other stress markers, including IRE, PERK and XBP, displayed similar patterns with MaCM treatment (data not shown). The expression levels of genes related to lipogenesis (FASBP4, 
FASN), lipolysis (LPL, LIPE), inflammation (IL6) as well as C/EBP and PPAR $\gamma$ increased during cell differentiation, confirming that differentiation occurs in both the presence and absence of MaCM.
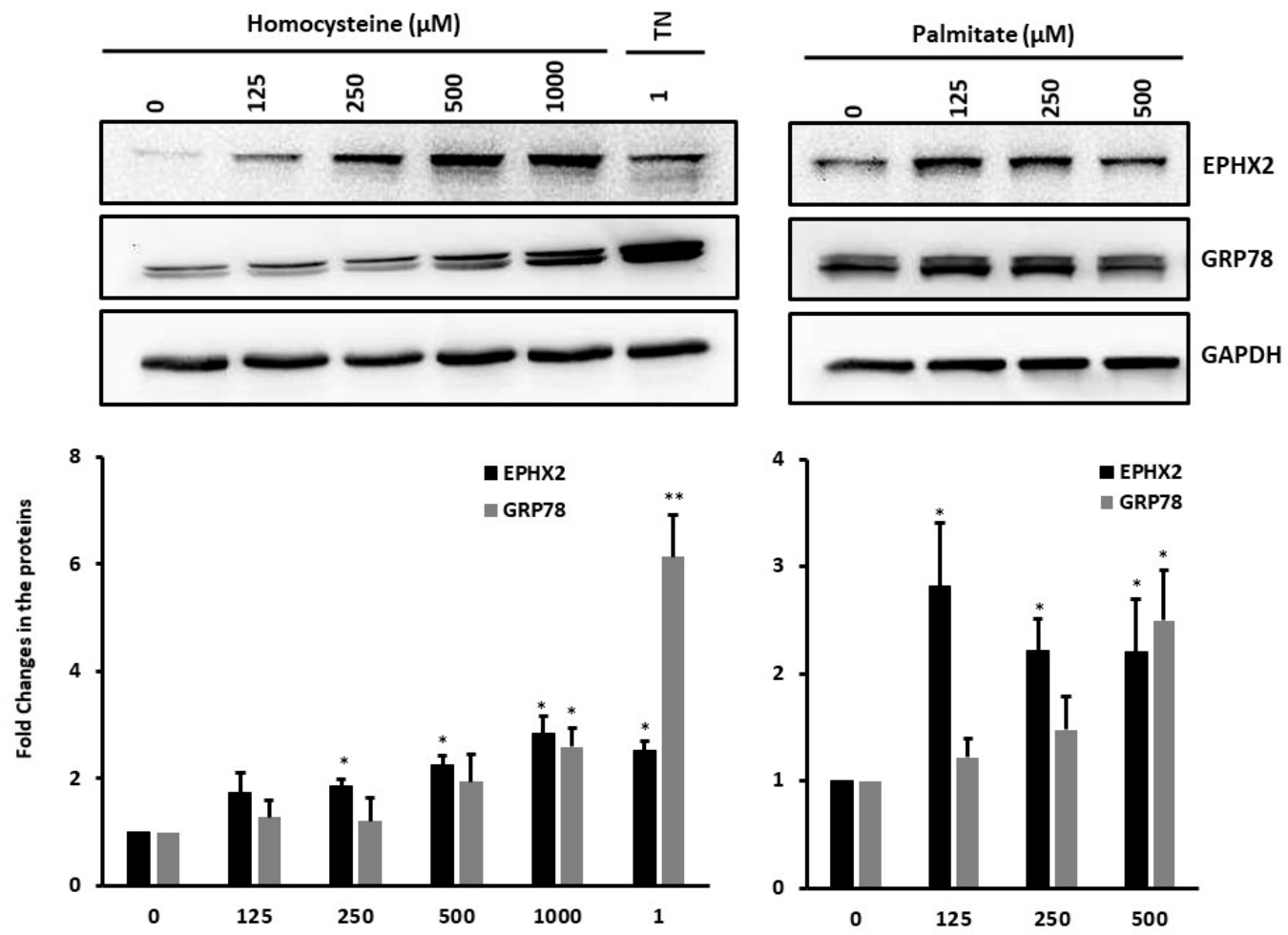

Figure 4. Expression levels of EPHX2 in 3T3-L1 preadipocytes under cellular stressor treatment. The protein levels were measured by Western Blot using 3T3-L1 preadipocytes treated overnight with various concentrations of homocysteine or palmitate or $1 \mu \mathrm{M}$ Tunicamycin (at least three independent experiments). GRP78 was used as a control for treatment efficacy. ${ }^{*} p<0.05 ;{ }^{* *} p<0.01$.
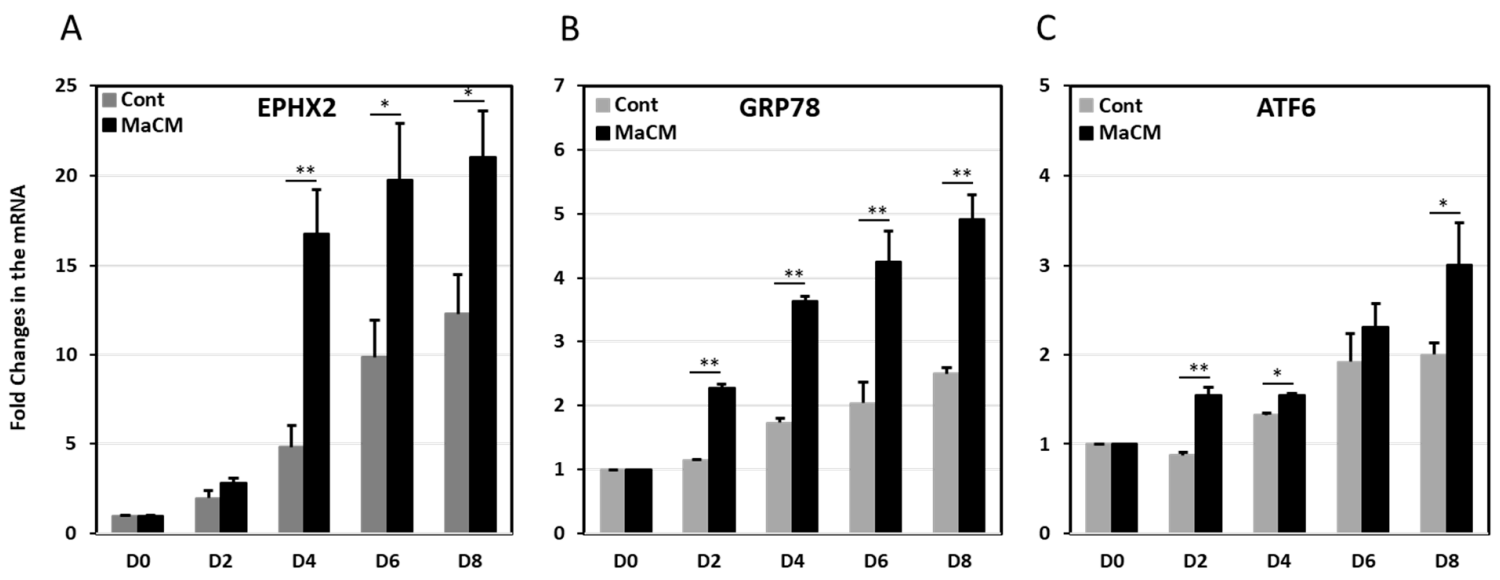

Figure 5. Expression levels of EPHX2 during the differentiation of 3T3-L1 preadipocytes and their treatment with a macrophage culture medium. mRNA expression levels of EPHX2 (A), GRP78 (B), and ATF6 (C) were measured by quantitative real-time PCR in 3T3-L1 preadipocytes (D0) and adipocytes differentiated for 8 days (D8) with and without macrophage-conditioned medium (MaCM). Data are presented as fold changes in differentiated adipocytes compared with preadipocytes from three independent experiments. ${ }^{*} p<0.05 ;{ }^{* *} p<0.01$. 


\section{Discussion}

Inflammation in adipose tissue has been proposed as a key factor in the mechanism underlying obesity-associated metabolic impairments [18]. With their action as immune cells, PBMCs also play a dynamic role in the crosstalk between adipose tissue and other organs in obesity [19]. Here, we observed a correlation between obesity and the expression levels of the pro-inflammatory enzyme EPHX2 in adipose tissue and PBMCs in humans, findings supported by our in vivo results. We observed a significantly elevated expression of EPHX2 and ER stress markers in both the SAT and PBMCs of obese individuals without diabetes as compared to normal-weight individuals. EPHX2 levels strongly correlated with adiposity and stress markers but negatively with a fitness indicator $\left(\mathrm{VO}_{2 \max }\right)$. In contrast, a 3-month supervised physical activity regimen significantly attenuated the expression of EPHX2 in both the SAT and PBMCs in obese subjects, with a parallel decrease in ER stress and inflammatory markers. EPHX2 levels also increased during differentiation in both human primary and 3T3-L1 mice preadipocytes. Finally, mediators of cellular stress (palmitate and homocysteine) also induced elevated EPHX2 expression in 3T3-L1 preadipocytes.

EPHX2 activity is considered a major determinant of the bioavailability of anti-inflammatory EET metabolites in the body [20]; thus, targeted inhibition of EPHX2 is an attractive approach to developing therapeutic agents. Numerous studies in animal models and cell lines have reported the involvement of EPHX2 in a variety of metabolic diseases, including cardiovascular diseases (CVD), hypertension, Non-alcoholic fatty liver disease (NAFLD), and diabetes, highlighting the potential benefits of its inhibition [1,21].

While the expression of EPHX2 is normally lower in adipose tissue than in liver or kidney, increased EPHX2 expression and activity were observed in a high-fat-diet-induced mouse model of obesity and during differentiation of murine adipocytes [22]. Consistent with these findings, we observed a marked elevation in EPHX2 levels in SAT of human obese subjects as compared to normal-weight controls. In addition, this increase strongly correlated with adiposity markers (BMI, waist, hip, and PBF), confirming the association between EPHX2 expression and obesity in humans, as observed in mouse models of obesity.

ER stress and inflammatory markers are elevated in the adipose tissue of obese humans [23-25]. We report here that the elevated EPHX2 levels in the SAT of obese subjects are accompanied by elevated levels of ER and cellular stress markers (GRP78, ATF6 $\alpha$, and HSP72). Interestingly, the knockdown of GRP78 significantly delayed adipocyte differentiation in 3T3-L1 preadipocytes [26], and GRP78 expression is elevated during adipocyte differentiation in pathological conditions [27] and in the SAT of diabetic patients [23]. The observed elevated levels of HSP72 could be explained by the fact that HSP72 binding increases IRE1 $\alpha /$ XBP1 signaling at the ER, thereby inhibiting ER-stress-induced apoptosis [28]. Accordingly, we previously suggested that the increased expression of HSP72 and other HSPs in the SAT and PBMCs of obese non-diabetic subjects is an adaptive response to cope with the ER and cellular stress [29]; this response is attenuated in diabetic subjects. Nevertheless, our results do not address whether the increased EPHX2 expression in our human obese subjects is directly caused by the metaflammation associated with this chronic condition. While inflammation and ER stress may increase EPHX2 expression, EPHX2 inhibition attenuates ER stress in insulin-sensitive tissues, especially the liver [30]. In this context, we showed here that the treatment of 3T3-L1 preadipocytes with classical ER stress (tunicamycin) and metabolic stressors (palmitate and homocysteine) increased EPHX2 expression in a concentration-dependent manner. Furthermore, MaCM treatment during the differentiation of 3T3-L1 cells induced an increased expression of EPHX2 and the ER stress markers GRP78 and ATF6. These data clearly show that metaflammation in adipose tissue plays a key role in the regulation of EPHX2 and ER stress markers and indicate potential contributions by both adipocytes and macrophages to this process.

Our finding of elevated EPHX2 expression in differentiating murine and human preadipocytes is consistent with a previous study reporting decreased EET levels during adipocyte differentiation in vitro and in the adipose tissue of diet-induced obese animals [31]. Our finding further supports 
the key role of EPHX2 expression and activity in decreasing EET levels; thus, their anti-inflammatory benefits in mature adipocytes as well as in obesity and its related metaflammation. Notably, EPHX2 genetic deficiency or pharmacological inhibition have been shown to attenuate diet-induced ER stress in the liver and adipose tissue of rodents $[32,33]$ and to suppress colonic inflammation induced by obesity [34]. Anti-diabetic drugs such as metformin and GLP-1 analogs, which result in decreased adiposity and cellular stress in humans, might act through decreasing EPHX2 expression or activity, a possibility that remains to be confirmed.

EPHX2 expression is reported to vary between different fat deposits. In epididymal fat isolated from mice, EPHX2 mRNA expression was four times higher in adipocytes than in the stroma [22]. Unfortunately, the volume of the SAT biopsies obtained from our subjects was too low to allow similar comparisons of EPHX2 expression in humans. In addition, we did not have access to visceral adipose deposits from these subjects. However, we suggest that EPHX2 expression levels are likely comparable between human VAT and SAT, as we observed similar EPHX2 levels in human preadipocytes from SAT and VAT and similar elevations in EPHX2 level during the differentiation of those primary cells (Figure 3).

Notably, the expression pattern of EPHX2 was sex-associated, with higher levels of EPHX2 observed in males both in SAT and PBMCs. This observation corroborates the reported sex-related dimorphic regulation of EET bioavailability in circulation and tissues, where both the increased CYP activity (EET synthesis) and decreased EPHX2 expression (EET degradation) observed in females are related to estrogen [35]. Accordingly, the potentiation of CYP/epoxygenase activity compensates for endothelial dysfunction in females, while the estrogen-dependent downregulation of EPHX2 expression yields divergent effects in the circulation (reviewed in [35]).

Physical activity is known to increase anti-inflammatory and stress responses and thus is useful for reducing the risk of chronic metabolic diseases and managing their related complications. Our data show that 3 months of regular physical activity significantly decreased EPHX2 levels in obese subjects, concomitant with decreased PBF, waist circumference, ER stress, and inflammation and increased $\mathrm{VO}_{2}$ max. The exercise-induced decrease in EPHX2 expression appeared to be global, as it was observed in both the SAT and PBMCs. Assessing EPHX2 expression in other tissues would be of interest. Interestingly, previous studies have reported that EET treatment prevented obesity-induced cardiomyopathy in $\mathrm{db} / \mathrm{db}$ mice by increasing $\mathrm{VO}_{2}$ max , with a concomitant decrease in $\mathrm{VCO}_{2} / \mathrm{VO}_{2}$, and exerted other metabolic effects [36]. In line with this improved oxygen consumption, mice fed a high-fat/high-fructose diet showed higher $\mathrm{VO}_{2} \max$ and greater weight loss after treatment with the EPHX2 inhibitor AR9281 [37].

The mechanism underlying the effect of exercise on EPHX2 expression is yet to be elucidated. The few previous studies of this relationship focused on the effect of exercise on EET availability but not on EPHX2. One such study used the EPHX2 inhibitor 1-trifluoromethoxyphenyl3-(1-propionylpiperidin-4-yl) urea (TPPU) in mice, reporting that an exercise-induced increase in EET expression exerts cardioprotection [38]. Another study reports lower EET levels in activity-restricted adult male rhesus macaques as compared to those with normal activity, which is likely due to higher EPHX2 activity [39]. In response to exercise, human plasma DHET levels are reported to increase in healthy subjects $[14,15]$. However, these studies provided no evidence that this effect resulted from impaired EPHX2 expression or activity. The only study focusing on EPHX2 modulation by exercise was reported in mice and showed decreased EPHX2 expression only in the kidney [40]. We and others have previously reported the beneficial effects of regular exercise in obese individuals $[17,41,42]$. Here, our exercising obese group showed increased maximal oxygen consumption along with improvements in the metabolic markers HDL, TG, glycemia, and stress response chaperones (GRP78 and HSP72), suggesting that the effects of our exercise protocol were global despite the negligible weight decrease and absence of a specific prescribed diet.

The present study is the first to report the effect of exercise on EXPH2 expression in obese humans, including the determination of the pattern of EPHX2 expression during adipocyte differentiation and 
under metabolic stress. Despite our novel findings, this study has some limitations. First, we did not have access to visceral adipose tissue biopsies, which would be more relevant to the pathophysiology of obesity and diabetes. Second, despite improvements in several fitness and metabolic markers, we cannot exclude the possibility that the lack of controlled dietary intake may have affected our interpretation of the EPHX2 levels and the efficacy of physical activity. Furthermore, the limited number of study participants does not allow for the generalization of our findings. Finally, we did not consider the potential contribution of the EPHX2 gene polymorphism in our data analysis, as we did not have access to this information. However, the strengths of this study include the involvement of a high-risk group of obese adults without T2D who underwent a supervised moderate exercise protocol as a behavioral approach to improve global health without diet restriction. Further studies are required to understand the crosstalk between EPHX2 levels and insulin resistance and the role of EPHX2 in adipose tissue, including its status in VAT. These studies will help to elucidate the mechanisms by which EPHX2 affects adiposity, insulin resistance, and diabetes.

\section{Materials and Methods}

\subsection{Study Population}

A total of 20 normal-weight (lean, $\left.20 \leq \mathrm{BMI}<25 \mathrm{~kg} / \mathrm{m}^{2}\right)$ and 20 obese $\left(30 \leq \mathrm{BMI}<40 \mathrm{~kg} / \mathrm{m}^{2}\right)$ adult individuals without diabetes were recruited to the study through the clinics of the Dasman Diabetes Institute (DDI), Kuwait. The protocol was approved by the Institutional Review Board of the DDI and was conducted in line with the principles of the Declaration of Helsinki. Written informed consent was obtained from all participants before enrollment in the study. Subjects with a history of major illness or medications or who performed regular physical activity within the last 6 months before study commencement were excluded.

\subsection{Exercise Protocol and Anthropometric Measurements}

Obese subjects were enrolled in a supervised exercise program at the Medical Fitness Center (MFC) of the DDI, as previously reported [43]. Before the first exercise session, each subject underwent the "CPET" cardiopulmonary exercise test (COSMED, Quark, Italy), which uses an ergometer to measure the maximum heart rate (max $\mathrm{HR})$ and maximum oxygen consumption $\left(\mathrm{VO}_{2} \max \right)$ during use of an electromagnetically-braked cycle. The exercise program combined resistance training with treadmill or cycling and moderate-intensity aerobic exercise. Each exercise session included $10 \mathrm{~min}$ of warming up and $10 \mathrm{~min}$ of cooling down at 50\%-60\% max HR in addition to the $40 \mathrm{~min}$ of described exercise at $65-80 \%$ max HR. Subjects exercised 3 times/week for a period of 3 months under the supervision and monitoring of fitness professionals at the MFC to maintain the recommended HR during the training. The effectiveness of the exercise regimen was assessed at the end of the 3-month program by comparison with parameters at the baseline.

\subsection{Blood and Tissue Sampling}

Venous peripheral blood and SAT biopsies were obtained at baseline and after the 3-months of exercise and were processed as previously reported [44]. Briefly, plasma and serum were prepared using vacutainer tubes for clinical analysis, and aliquots were stored at $-80^{\circ} \mathrm{C}$. PBMCs were prepared from fresh blood samples collected in Ethylenediamine tetraacetic acid (EDTA) tubes. PBMCs were isolated using Ficoll-Hypaque density-gradient centrifugation. SAT biopsies specimens $(\sim 300 \mathrm{mg})$ were obtained from the periumbilical area by surgical biopsy after local anesthesia. The specimens were then rinsed in cold PBS, divided into 4 pieces, and stored appropriately until assayed.

\subsection{Blood Biochemistry}

Concentrations of blood clinical markers and plasma inflammatory and metabolic markers were measured as previously reported [44]. Briefly, the $\mathrm{HbA1c}$ level was determined using the 
variant device (Bio-Rad, Hercules, CA, USA). Glucose and lipid concentrations were measured on the Siemens Dimension RXL chemistry analyzer (Diamond Diagnostics, Holliston, MA, USA). Plasma concentrations of inflammatory markers were measured using a Bioplex-200 multiplexing technology system (BioRad, Hercules, CA, USA). High-sensitivity CRP (hsCRP) concentrations were determined by ELISA (Biovendor ELISA kit, Asheville, NC, USA). Circulating GRP78 and HSP72 protein concentrations were determined in plasma using the human ELISA kit (Enzo LifeSciences, Lausen, Switzerland). All assays were performed according to the manufacturers' instructions.

\subsection{Immunohistochemical and Immunofluorescence Analyses}

Formalin-fixed, paraffin-embedded SAT sections were used for immunohistochemical analysis and immunofluorescence investigations ( $n=5$ each), as previously described [23]. For the immunohistochemical analysis, we used anti-GRP78 (Abcam, Cambridge, MA, USA), Imgenex anti-ATF6 (Novus, Littleton, CO, USA), and anti-EPHX2 antibodies (OriGene Technologies, Inc., Rockville, MD, USA). The immunohistochemical analysis results were quantified using ImageScope software version 11.1 (Aperio, Vista, CA, USA), as previously reported [29]. For immunofluorescent staining, tissue sections were incubated with anti-GRP78 or anti-ATF6 antibody conjugated with Alexa Fluor-488 (Bioss, Woburn, MA, USA). EPHX2 tissue sections were incubated with anti-EPHX2 antibody (OriGene Technologies, Inc., Rockville, USA) and then incubated with Alexa Fluor-488-conjugated goat anti-mouse secondary antibody (Molecular Probes, ThermoFisher, USA). Nuclei were stained using $0.05 \%$ DAPI. The sections were viewed with a Zeiss LSM 710 confocal laser-scanning microscope, and representative areas of the sections were photographed under a $40 \times$ objective.

\subsection{Cell Cultures}

Mouse preadipocytes (3T3-L1) and macrophages (RAW264.7) were obtained from American Type Culture Collection (ATCC) (Manassas, VA, USA), cultured, and induced to differentiate in a growth medium as previously reported [17]. For indirect co-culture of 3T3L1 and RAW264.7 cells, media from RAW264.7 cells were collected and sterile filtered $(0.2 \mu \mathrm{m})$. The differentiation of 3T3-L1 cells was induced using MaCM supplemented with a differentiation cocktail (1\% PS, 10\% bovine calf serum (BCS), $0.5 \mathrm{mM}$ 3-isobutyl1-methylxanthine, $1 \mu \mathrm{M}$ dexamethasone, and $1 \mu \mathrm{g} / \mathrm{mL}$ insulin) for 2 days. The medium was then changed to MaCM with $10 \%$ BCS and insulin $(1 \mu \mathrm{g} / \mathrm{mL})$ and was replaced every 2 days through day 8 . At least 3 independent experiments were performed for each condition. Human primary preadipocyte cells from hSAT and hVAT (\#PT5001 and \#PT5005, Lonza, Walkersville, MD, USA) were processed and differentiated according to the supplier's instructions in 2 independent experiments.

\subsection{Quantitative Real-Time PCR}

Total RNA was extracted from SAT ( $n=10$ each subject group) using the RNeasy Lipid Tissue MiniKit (Qiagen, Hilden, Germany). Total RNA from PBMCs ( $n=10$ each subject group), cell lines (3 independent experiments), and primary adipocytes ( 2 independent experiments) was extracted using TRIZOL reagent. cDNA was synthesized from total RNA samples using the High Capacity cDNA Reverse Transcription Kit (Applied Biosystems, Foster City, CA, USA). Conventional qRT-PCR was performed using the Applied Biosystem7500 system, and gene expression was normalized to that of GADPH. The primers used are presented in Table S1. Differences in gene expression between groups were assessed using the $\Delta \Delta C T$ method.

\subsection{Western Blot Analysis}

Western Blot analysis was performed using PBMCs from lean and obese subjects (at least $n=9$ for each group), differentiated 3T3-L1 cells, and 3T3-L1 preadipocytes as previously reported [43] ( 3 independent experiments). Briefly, whole cell extracts were prepared in RIPA buffer, and protein concentration was determined using the Bradford method using $\beta$-globulin as a standard. Protein 
samples $(20 \mu \mathrm{g})$ were loaded and resolved on $12 \%$ SDS-PAGE gels. After transfer to PVDF membranes, the proteins were probed with anti-GRP78 (Abcam, Cambridge, MA, USA) and anti-EPHX2 antibodies (OriGene Technologies, Inc., Rockville, MD, USA) overnight at $4{ }^{\circ} \mathrm{C}$. After washing, the membranes were incubated with rabbit horseradish-peroxidase-conjugated secondary antibody for $2 \mathrm{~h}$ at room temperature and the proteins visualized using super sensitivity West Femto-ECL reagent (Thermo Scientific, Waltham, MA, USA). Protein bands were visualized by chemiluminescence and the images captured using the Versadoc 5000 system (Bio-Rad), and the bands intensity was determined using Quantity One Software (Bio-Rad). GAPDH was used as an internal control for protein loading and was detected with an anti-GAPDH antibody (ab2302; Millipore, Temecula, CA, USA).

\subsection{Oil Red O Staining}

3T3-L1 cells were washed twice with PBS, fixed with $10 \%$ formalin for $1 \mathrm{~h}$ at RT, washed twice again with PBS, and incubated with $60 \%$ isopropanol for $5 \mathrm{~min}$. Finally, cells were incubated with $0.3 \%$ Oil Red O solution for $20 \mathrm{~min}$. Coverslips were washed with distilled water five times and mounted onto a slide. Images were captured using a panoramic digital slide scanner.

\subsection{AdipoRed Assay}

Human primary preadipocyte cells from hSAT and hVAT were plated and left overnight to attach. Then, AdipoRed Assay Reagent (Lonza, Walkersville, MD, USA) was used to stain the cells following the manufacturer's instructions. Images were captured using a digital camera.

\subsection{Statistical Analysis}

Statistical analyses were performed using SPSS software (v25.0; SPSS Inc., IL, USA). Descriptive statistics are reported here as the mean \pm standard error. The Chi-square test was used for categorical variables, and the Wilcoxon non-parametric $t$-test was used for skewed and continuous variables. The paired $t$-test was used to determine the significance of differences between means within the obese group before and after exercise. Spearman's correlation coefficient was used to assess the correlations between variables. $p<0.05$ was considered statistically significant.

\subsection{Ethics Approval and Consent to Participate}

Written informed consent was obtained from all participants prior to starting this study (RA-2010-003, 18 May 2010), which was approved by the Review Board of Dasman Diabetes Institute and was conducted in line with the principles of the Declaration of Helsinki.

Supplementary Materials: The following are available online at http://www.mdpi.com/1422-0067/21/6/2056/s1.

Author Contributions: A.K. and A.T. designed the study. S.K., D.M., and P.C. performed the experiments. A.K., S.K., and A.T. analyzed the data, wrote, and revised the manuscript. F.A.-M. and J.A. revised the manuscript. All authors have read and agreed to the published version of the manuscript.

Funding: This research was funded by the Kuwait Foundation for the Advancement of Sciences under project (RA-2010-003).

Acknowledgments: This work was supported by the Kuwait Foundation for the Advancement of Sciences under project (RA-2010-003). We thank the staff at the Fitness and Rehabilitation Center, the Clinical Laboratory and BioBank at Dasman Diabetes Institute for their help throughout the present study. We also thank Valerie Lopez (Biobank) for tissue slide preparation. Maha Hammad is thanked for performing the AdipoRed Assay. Enago (www.enago.com) is thanked for the English language review.

Conflicts of Interest: The authors declare no conflict of interest. 


\section{Abbreviations}

$\begin{array}{ll}\text { DBP } & \text { diastolic blood pressure } \\ \text { EPHX2 } & \text { epoxide hydrolase 2 } \\ \text { HbA1c } & \text { hemoglobin A1c; } \\ \text { HDL } & \text { high-density lipoprotein } \\ \text { HR } & \text { heart rate } \\ \text { hSCRP } & \text { high-sensitivity CRP } \\ \text { LDL } & \text { low-density lipoprotein; } \\ \text { PBF } & \text { percent body fat } \\ \text { SAT } & \text { subcutaneous adipose tissue } \\ \text { PBMC } & \text { peripheral blood mononuclear cell; } \\ \text { sEH } & \text { soluble epoxide hydrolase; } \\ \text { SBP } & \text { systolic blood pressure; } \\ \text { TGL } & \text { triglyceride } \\ \text { VO } 2 \text { max } & \text { maximum oxygen consumption; } \\ \text { WC } & \text { waist circumference. }\end{array}$

\section{References}

1. He, J.; Wang, C.; Zhu, Y.; Ai, D. Soluble epoxide hydrolase: A potential target for metabolic diseases. J. Diabetes 2016, 8, 305-313. [CrossRef] [PubMed]

2. Das, U.N. Arachidonic acid in health and disease with focus on hypertension and diabetes mellitus: A review. J. Adv. Res. 2018, 11, 43-55. [CrossRef] [PubMed]

3. Shen, H.C.; Hammock, B.D. Discovery of inhibitors of soluble epoxide hydrolase: A target with multiple potential therapeutic indications. J. Med. Chem. 2012, 55, 1789-1808. [CrossRef]

4. Luther, J.M.; Brown, N.J. Epoxyeicosatrienoic acids and glucose homeostasis in mice and men. Prostaglandins Other Lipid Mediat 2016, 125, 2-7. [CrossRef]

5. Lee, C.R.; North, K.E.; Bray, M.S.; Fornage, M.; Seubert, J.M.; Newman, J.W.; Hammock, B.D.; Couper, D.J.; Heiss, G.; Zeldin, D.C. Genetic variation in soluble epoxide hydrolase (ephx2) and risk of coronary heart disease: The atherosclerosis risk in communities (aric) study. Hum. Mol Genet. 2006, 15, 1640-1649. [CrossRef]

6. Hancock, A.M.; Witonsky, D.B.; Gordon, A.S.; Eshel, G.; Pritchard, J.K.; Coop, G.; Di Rienzo, A. Adaptations to climate in candidate genes for common metabolic disorders. PLoS Genet. 2008, 4, e32. [CrossRef]

7. Yang, L.; Maki-Petaja, K.; Cheriyan, J.; McEniery, C.; Wilkinson, I.B. The role of epoxyeicosatrienoic acids in the cardiovascular system. Br. J. Clin. Pharmacol. 2015, 80, 28-44. [CrossRef] [PubMed]

8. Ramirez, C.E.; Shuey, M.M.; Milne, G.L.; Gilbert, K.; Hui, N.; Yu, C.; Luther, J.M.; Brown, N.J. Arg287gln variant of ephx2 and epoxyeicosatrienoic acids are associated with insulin sensitivity in humans. Prostaglandins Other Lipid Mediat 2014, 113-115, 38-44. [CrossRef] [PubMed]

9. Ohtoshi, K.; Kaneto, H.; Node, K.; Nakamura, Y.; Shiraiwa, T.; Matsuhisa, M.; Yamasaki, Y. Association of soluble epoxide hydrolase gene polymorphism with insulin resistance in type 2 diabetic patients. Biochem. Biophys. Res. Commun. 2005, 331, 347-350. [CrossRef]

10. Yang, J.; Oh, Y.T.; Wan, D.; Watanabe, R.M.; Hammock, B.D.; Youn, J.H. Postprandial effect to decrease soluble epoxide hydrolase activity: Roles of insulin and gut microbiota. J. Nutr. Biochem. 2017, 49, 8-14. [CrossRef]

11. Jakicic, J.M.; Rogers, R.J.; Davis, K.K.; Collins, K.A. Role of physical activity and exercise in treating patients with overweight and obesity. Clin. Chem. 2018, 64, 99-107. [CrossRef]

12. Neufer, P.D.; Bamman, M.M.; Muoio, D.M.; Bouchard, C.; Cooper, D.M.; Goodpaster, B.H.; Booth, F.W.; Kohrt, W.M.; Gerszten, R.E.; Mattson, M.P.; et al. Understanding the cellular and molecular mechanisms of physical activity-induced health benefits. Cell Metab. 2015, 22, 4-11. [CrossRef]

13. Pucci, B.; Villanova, L.; Sansone, L.; Pellegrini, L.; Tafani, M.; Carpi, A.; Fini, M.; Russo, M.A. Sirtuins: The molecular basis of beneficial effects of physical activity. Intern. Emerg Med. 2013, 8 (Supp. 1), S23-S25. [CrossRef]

14. Giordano, R.M.; Newman, J.W.; Pedersen, T.L.; Ramos, M.I.; Stebbins, C.L. Effects of dynamic exercise on plasma arachidonic acid epoxides and diols in human volunteers. Int. J. Sport Nutr. Exerc. Metab. 2011, 21, 471-479. [CrossRef] 
15. Gollasch, B.; Dogan, I.; Rothe, M.; Gollasch, M.; Luft, F.C. Maximal exercise and plasma cytochrome p450 and lipoxygenase mediators: A lipidomics study. Physiol. Rep. 2019, 7, e14165. [CrossRef] [PubMed]

16. Hellsten, Y.; Nyberg, M.; Jensen, L.G.; Mortensen, S.P. Vasodilator interactions in skeletal muscle blood flow regulation. J. Physiol. 2012, 590, 6297-6305. [CrossRef] [PubMed]

17. Khadir, A.; Kavalakatt, S.; Madhu, D.; Hammad, M.; Devarajan, S.; Tuomilehto, J.; Tiss, A. Fetuin-a levels are increased in the adipose tissue of diabetic obese humans but not in circulation. Lipids Health Dis. 2018, 17, 291. [CrossRef] [PubMed]

18. Xu, H.; Barnes, G.T.; Yang, Q.; Tan, G.; Yang, D.; Chou, C.J.; Sole, J.; Nichols, A.; Ross, J.S.; Tartaglia, L.A.; et al. Chronic inflammation in fat plays a crucial role in the development of obesity-related insulin resistance. J. Clin. Investig. 2003, 112, 1821-1830. [CrossRef] [PubMed]

19. Liu, R.; Nikolajczyk, B.S. Tissue immune cells fuel obesity-associated inflammation in adipose tissue and beyond. Front. Immunol. 2019, 10, 1587. [CrossRef] [PubMed]

20. Imig, J.D.; Hammock, B.D. Soluble epoxide hydrolase as a therapeutic target for cardiovascular diseases. Nat. Rev. Drug Discov. 2009, 8, 794-805. [CrossRef] [PubMed]

21. Lorthioir, A.; Guerrot, D.; Joannides, R.; Bellien, J. Diabetic cvd-soluble epoxide hydrolase as a target. Cardiovasc. Hematol. Agents Med. Chem. 2012, 10, 212-222. [CrossRef] [PubMed]

22. De Taeye, B.M.; Morisseau, C.; Coyle, J.; Covington, J.W.; Luria, A.; Yang, J.; Murphy, S.B.; Friedman, D.B.; Hammock, B.B.; Vaughan, D.E. Expression and regulation of soluble epoxide hydrolase in adipose tissue. Obesity (Silver Spring) 2010, 18, 489-498. [CrossRef] [PubMed]

23. Khadir, A.; Kavalakatt, S.; Abubaker, J.; Cherian, P.; Madhu, D.; Al-Khairi, I.; Abu-Farha, M.; Warsame, S.; Elkum, N.; Dehbi, M.; et al. Physical exercise alleviates er stress in obese humans through reduction in the expression and release of grp78 chaperone. Metabolism 2016, 65, 1409-1420. [CrossRef]

24. Sharma, N.K.; Das, S.K.; Mondal, A.K.; Hackney, O.G.; Chu, W.S.; Kern, P.A.; Rasouli, N.; Spencer, H.J.; Yao-Borengasser, A.; Elbein, S.C. Endoplasmic reticulum stress markers are associated with obesity in nondiabetic subjects. J. Clin. Endocrinol. Metab. 2008, 93, 4532-4541. [CrossRef] [PubMed]

25. Boden, G.; Duan, X.; Homko, C.; Molina, E.J.; Song, W.; Perez, O.; Cheung, P.; Merali, S. Increase in endoplasmic reticulum stress-related proteins and genes in adipose tissue of obese, insulin-resistant individuals. Diabetes 2008, 57, 2438-2444. [CrossRef] [PubMed]

26. Zhu, G.; Ye, R.; Jung, D.Y.; Barron, E.; Friedline, R.H.; Benoit, V.M.; Hinton, D.R.; Kim, J.K.; Lee, A.S. Grp78 plays an essential role in adipogenesis and postnatal growth in mice. FASEB J. 2013, 27, 955-964. [CrossRef] [PubMed]

27. Longo, M.; Spinelli, R.; D’Esposito, V.; Zatterale, F.; Fiory, F.; Nigro, C.; Raciti, G.A.; Miele, C.; Formisano, P.; Beguinot, F.; et al. Pathologic endoplasmic reticulum stress induced by glucotoxic insults inhibits adipocyte differentiation and induces an inflammatory phenotype. Biochim. Biophys. Acta 2016, 1863, 1146-1156. [CrossRef]

28. Gupta, S.; Deepti, A.; Deegan, S.; Lisbona, F.; Hetz, C.; Samali, A. Hsp72 protects cells from er stress-induced apoptosis via enhancement of irelalpha-xbp1 signaling through a physical interaction. PLoS Biol. 2010, 8 , e1000410. [CrossRef]

29. Tiss, A.; Khadir, A.; Abubaker, J.; Abu-Farha, M.; Al-Khairi, I.; Cherian, P.; John, J.; Kavalakatt, S.; Warsame, S.; Al-Ghimlas, F; et al. Immunohistochemical profiling of the heat shock response in obese non-diabetic subjects revealed impaired expression of heat shock proteins in the adipose tissue. Lipids Health Dis. 2014, 13, 106. [CrossRef]

30. Lopez-Vicario, C.; Alcaraz-Quiles, J.; Garcia-Alonso, V.; Rius, B.; Hwang, S.H.; Titos, E.; Lopategi, A.; Hammock, B.D.; Arroyo, V.; Claria, J. Inhibition of soluble epoxide hydrolase modulates inflammation and autophagy in obese adipose tissue and liver: Role for omega-3 epoxides. Proc. Natl. Acad. Sci. USA 2015, 112, 536-541. [CrossRef]

31. Zha, W.; Edin, M.L.; Vendrov, K.C.; Schuck, R.N.; Lih, F.B.; Jat, J.L.; Bradbury, J.A.; DeGraff, L.M.; Hua, K.; Tomer, K.B.; et al. Functional characterization of cytochrome p450-derived epoxyeicosatrienoic acids in adipogenesis and obesity. J. Lipid Res. 2014, 55, 2124-2136. [CrossRef] [PubMed]

32. Harris, T.R.; Bettaieb, A.; Kodani, S.; Dong, H.; Myers, R.; Chiamvimonvat, N.; Haj, F.G.; Hammock, B.D. Inhibition of soluble epoxide hydrolase attenuates hepatic fibrosis and endoplasmic reticulum stress induced by carbon tetrachloride in mice. Toxicol. Appl. Pharmacol. 2015, 286, 102-111. [CrossRef] [PubMed] 
33. Bettaieb, A.; Nagata, N.; AbouBechara, D.; Chahed, S.; Morisseau, C.; Hammock, B.D.; Haj, F.G. Soluble epoxide hydrolase deficiency or inhibition attenuates diet-induced endoplasmic reticulum stress in liver and adipose tissue. J. Biol. Chem. 2013, 288, 14189-14199. [CrossRef] [PubMed]

34. Wang, W.; Yang, J.; Zhang, J.; Wang, Y.; Hwang, S.H.; Qi, W.; Wan, D.; Kim, D.; Sun, J.; Sanidad, K.Z.; et al. Lipidomic profiling reveals soluble epoxide hydrolase as a therapeutic target of obesity-induced colonic inflammation. Proc. Natl. Acad. Sci. USA 2018, 115, 5283-5288. [CrossRef]

35. Huang, A.; Sun, D. Sexually dimorphic regulation of eet synthesis and metabolism: Roles of estrogen. Front. Pharmacol. 2018, 9, 1222. [CrossRef]

36. Cao, J.; Singh, S.P.; McClung, J.A.; Joseph, G.; Vanella, L.; Barbagallo, I.; Jiang, H.; Falck, J.R.; Arad, M.; Shapiro, J.I.; et al. Eet intervention on wnt1, nov, and ho-1 signaling prevents obesity-induced cardiomyopathy in obese mice. Am. J. Physiol. Heart Circ. Physiol. 2017, 313, H368-H380. [CrossRef]

37. do Carmo, J.M.; da Silva, A.A.; Morgan, J.; Jim Wang, Y.X.; Munusamy, S.; Hall, J.E. Inhibition of soluble epoxide hydrolase reduces food intake and increases metabolic rate in obese mice. Nutr. Metab. Cardiovasc. Dis. 2012, 22, 598-604. [CrossRef]

38. Guo, Y.; Luo, F.; Zhang, X.; Chen, J.; Shen, L.; Zhu, Y.; Xu, D. Tppu enhanced exercise-induced epoxyeicosatrienoic acid concentrations to exert cardioprotection in mice after myocardial infarction. J. Cell Mol. Med. 2018, 22, 1489-1500. [CrossRef]

39. Chadderdon, S.M.; Belcik, J.T.; Smith, E.; Pranger, L.; Kievit, P.; Grove, K.L.; Lindner, J.R. Activity restriction, impaired capillary function, and the development of insulin resistance in lean primates. Am. J. Physiol. Endocrinol. Metab. 2012, 303, E607-E613. [CrossRef]

40. Stanford, K.I.; Lynes, M.D.; Takahashi, H.; Baer, L.A.; Arts, P.J.; May, F.J.; Lehnig, A.C.; Middelbeek, R.J.W.; Richard, J.J.; So, K.; et al. 12,13-dihome: An exercise-induced lipokine that increases skeletal muscle fatty acid uptake. Cell Metab. 2018, 27, 1111-1120. [CrossRef]

41. Blaak, E.E.; van Aggel-Leijssen, D.P.; Wagenmakers, A.J.; Saris, W.H.; van Baak, M.A. Impaired oxidation of plasma-derived fatty acids in type 2 diabetic subjects during moderate-intensity exercise. Diabetes 2000, 49, 2102-2107. [CrossRef] [PubMed]

42. Khadir, A.; Kavalakatt, S.; Cherian, P.; Warsame, S.; Abubaker, J.A.; Dehbi, M.; Tiss, A. Physical exercise enhanced heat shock protein 60 expression and attenuated inflammation in the adipose tissue of human diabetic obese. Front. Endocrinol. (Lausanne) 2018, 9, 16. [CrossRef] [PubMed]

43. Kavalakatt, S.; Khadir, A.; Madhu, D.; Hammad, M.; Devarajan, S.; Abubaker, J.; Al-Mulla, F.; Tuomilehto, J.; Tiss, A. Urocortin 3 levels are impaired in overweight humans with and without type 2 diabetes and modulated by exercise. Front. Endocrinol. 2019, 10. [CrossRef] [PubMed]

44. Khadir, A.; Tiss, A.; Abubaker, J.; Abu-Farha, M.; Al-Khairi, I.; Cherian, P.; John, J.; Kavalakatt, S.; Warsame, S.; Al-Madhoun, A.; et al. Map kinase phosphatase dusp1 is overexpressed in obese humans and modulated by physical exercise. Am. J. Physiol. Endocrinol. Metab. 2015, 308, E71-E83. [CrossRef] [PubMed] 